\title{
(2) OPEN ACCESS \\ Addressing challenges in \\ humanitarian surgical care through hackathons: report on a Tokyo hackathon and the award-winning projects it generated
}

Michiko Kyokan (D) , Fumiaki Ikeno, $^{2}$ Masakazu Yagi, ${ }^{3}$ Stefano Di Carlo ${ }^{1}$

${ }^{1}$ Innovation Unit, Medecins Sans Frontieres, Tokyo, Japan 2Division of Cardiovascular Medicine, Stanford University, Stanford, California, USA

${ }^{3}$ Graduate School of Medicine, Osaka University, Osaka, Japan

\section{Correspondence to} Michiko Kyokan, Innovation Unit, Medecins Sans Frontieres, Tokyo, Japan; m.kyokan@tokyo. msf.org

Accepted 25 July 2020 Published Online First 13 August 2020
D) Check for updates

(c) Author(s) (or their employer(s)) 2020. Re-use permitted under CC BY-NC. No commercial re-use. See rights and permissions. Published by BMJ.

To cite: Kyokan M, Ikeno F, Yagi $M$, et al. BMJ Innov 2020;6:123-126.

\section{INTRODUCTION}

In September 2017, Médecins Sans Frontières (MSF) held a hackathon-a concentrated event that brings together various professionals and end users to build innovative solutions to challenges end users face in their work ${ }^{1}$-in Tokyo for 2 days. The event aimed (1) to identify new ideas to address challenges in humanitarian surgical care and (2) to deepen innovation networks in the humanitarian medical aid sector. This paper describes how MSF organised the hackathon and subsequently supported four projects launched at the event. The paper shares lessons learnt based on this experience for others holding hackathons with similar aims.

\section{CHALLENGE SELECTION}

To identify the challenges to tackle in the hackathon, we interviewed a range of surgical experts within MSF. Numerous challenges were raised. Following the Field Guide To Human-Centred Design, we tried and devised five possible solutions to each challenge in just a few minutes $^{2}$ : this tests their suitability for a hackathon-type event. We also narrowed the scope of our challenges by giving them a specific context while still trying to provide enough latitude for creative solutions to emerge.

\section{MENTORS AND PARTICIPANTS}

MSF asked Japan Biodesign-a partner of the Stanford University Biodesign programme with trained leaders in innovating medical devices using design thinking principles ${ }^{3}$ - to mentor participants. MSF surgical care experts also provided medical advice. Fifty-seven people, comprising medical professionals, engineers, developers, business people and students, were recruited mostly from MSF and Biodesign's own networks. While several participants worked at medical device companies, all came representing themselves.

\section{GROUP WORK}

Mentors strongly encouraged participant groups to employ principles of design thinking. In contrast to more conventional hackathons, ${ }^{4}$ therefore, participants began the hackathon by thoroughly investigating and fully deconstructing their chosen problem and identifying the specific needs arising therein. Only then did they ideate solutions.

\section{AWARDS}

We employed three specific criteria to judge solutions: originality, impact and viability. Our four winning teams each received money for materials and technical and clinical advice. Furthermore, MSF and Japan Biodesign gave significant support to these teams to advance their projects further. However, as shown in table 1 , after 2 years, none of the teams remain active. We return to this later.

\section{Following up the award-winning teams}

After the hackathon, members of winning teams worked on their projects as volunteers. Teams 1 and 4 met regularly and advanced their ideas significantly. Team 1 developed their specification for a headlamp and received generous support from a medium-sized enterprise to build 


\begin{tabular}{|c|c|c|c|}
\hline Team & Challenge & Solution & Project status 2 years after the hackathon \\
\hline 1 & $\begin{array}{l}\text { MSF surgeons sometimes use a headlamp for } \\
\text { surgery, not only with a surgical light but also as } \\
\text { a main light during power cuts. However, medical } \\
\text { headlamps are expensive and outdoor headlamps } \\
\text { are often used. Is there a way to provide an } \\
\text { appropriate surgical headlamp for surgeons in } \\
\text { humanitarian surgical care? }\end{array}$ & $\begin{array}{l}\text { An affordable headlamp with adequate lighting } \\
\text { focus for surgery using modern LED technology } \\
\text { that might even replace expensive free-standing } \\
\text { surgical lights in the future }\end{array}$ & $\begin{array}{l}\text { The team met bimonthly for a year and } \\
\text { developed specifications for a surgical headlamp. } \\
\text { They developed an early-stage prototype } \\
\text { and tested it with a few surgeons. However, } \\
\text { refinement of the prototype was not possible } \\
\text { because of its technological difficulties. The } \\
\text { project stopped at this stage. }\end{array}$ \\
\hline 2 & $\begin{array}{l}\text { Surgical drills are expensive and often } \\
\text { unavailable in low-resource settings, forcing } \\
\text { hospitals to resort to inefficient hand drills, which } \\
\text { require more time and effort. Is there a way to } \\
\text { drill bones in humanitarian surgical care in order } \\
\text { to perform bone surgery safely but affordably? }\end{array}$ & $\begin{array}{l}\text { A drill cover that makes any DIY drill suitable for } \\
\text { surgical use }\end{array}$ & $\begin{array}{l}\text { The team met only once after the event. } \\
\text { Around the same time, another company, } \\
\text { which produces a similar product, had raised } \\
\text { substantial funding and was willing to adapt its } \\
\text { product to suit MSF's needs. So the team and } \\
\text { MSF decided to discontinue the project. }\end{array}$ \\
\hline 3 & $\begin{array}{l}\text { Using surgical scissors that are not sharp enough } \\
\text { is a common frustration for surgeons in MSF. } \\
\text { How can we keep surgical scissors in optimal } \\
\text { condition? }\end{array}$ & $\begin{array}{l}\text { A tag identification system: this allows scissors to } \\
\text { be sorted according to sharpness and those that } \\
\text { do not cut well to be removed from the operation } \\
\text { room supply system }\end{array}$ & $\begin{array}{l}\text { The team conducted a survey to further } \\
\text { investigate the problem. An interesting finding } \\
\text { was that local staff do not necessarily know } \\
\text { how to properly choose and use different types } \\
\text { of scissors, which may cause damage to the } \\
\text { scissors. While the team is not active anymore, } \\
\text { MSF is investigating their findings further. }\end{array}$ \\
\hline 4 & $\begin{array}{l}\text { After surgery, patients are transferred to a ward } \\
\text { where medical staff are scarce. Observation is } \\
\text { intermittent as continuous monitoring for each } \\
\text { patient is too expensive. Surgeons are frustrated } \\
\text { that patient observation is not adequate. How } \\
\text { can we ensure appropriate observation of } \\
\text { patients after surgery? }\end{array}$ & $\begin{array}{l}\text { A state-of-the-art camera device: this monitors } \\
\text { several vital signs and the data are shown on a } \\
\text { smartphone or tablet }\end{array}$ & $\begin{array}{l}\text { The proposal was named a 'moon-shot', with } \\
\text { its far-sighted monitoring technology. However, } \\
\text { the iteration process to make the solution } \\
\text { realistically low-tech meant that its clinical } \\
\text { impact became questionable. This modified } \\
\text { solution did not raise enough interest for MSF } \\
\text { to invest further in it. The interest of the team } \\
\text { diminished to continue iterating the concept. }\end{array}$ \\
\hline
\end{tabular}

DIY, do-it-yourself; LED, light-emitting diode; MSF, Médecins Sans Frontières.

a prototype. However, that prototype did not meet all necessary design criteria, and the team was unable to reiterate to overcome certain technological difficulties. Team 4, in contrast, dramatically reiterated to make their initial, highly sophisticated proposal more feasible for the contexts in which MSF works. However, the revised solution's impact was too limited for MSF's purposes. Team 4 did not reiterate the concept thereafter as the interest of the team diminished to continue working.

Team 2 held only one meeting. Around the same time, another company approached MSF and offered to adapt a similar existing product for MSF's needs. MSF is pursuing this further; thus, MSF and team 2 decided not to continue their project.

Team 3, pushed mostly by one very motivated individual, elected to investigate their problem further by conducting a survey of MSF surgeons. That research found that improper use of different types of scissors might be damaging them. However, the team leader was reassigned within his company and was unable to continue managing this project. Lacking this leadership, the team disbanded; however, MSF continues to investigate these findings internally.

\section{LESSONS LEARNT}

Our experience highlights four lessons learnt, which are described further in detail. Recommendations based on the lessons learnt are summarised in figure 1 .

\section{Select appropriately scoped challenges}

Commentators note that if a challenge is too broad and/ or complex, hackathon participants struggle to narrow the scope sufficiently to enable them to start work. ${ }^{2}$ However, a challenge that is too specific will limit room to explore creative solutions. ${ }^{2}$ So what is the proper balance? For organisations that are relatively new to facilitating hackathons-like MSF-leaning towards a relatively narrow scope and low complexity appears advisable. 'A way to provide an appropriate surgical headlamp for surgeons in humanitarian surgical care', which team 1 chose to address, exemplifies this. Here, the narrow scope and low complexity fostered a rapid reiteration process that gave momentum to the project and thus ensured the continued engagement of the team. In contrast, 'a way to enable MSF surgeons to obtain new skills to perform better and more types of surgery in the field' proved too broad and difficult a challenge to scope down ahead of a thorough problem analysis within the hackathon's time limits.

\section{Find alternative ways to explain problems in humanitarian contexts}

Participants' general unfamiliarity with humanitarian medical work was a significant challenge to problem analysis. MSF has since experimented with alternative ways to explain the problems at the core of the challenges selected for the hackathon. At another event hosted by Japan Biodesign and MSF in June 2019, the 


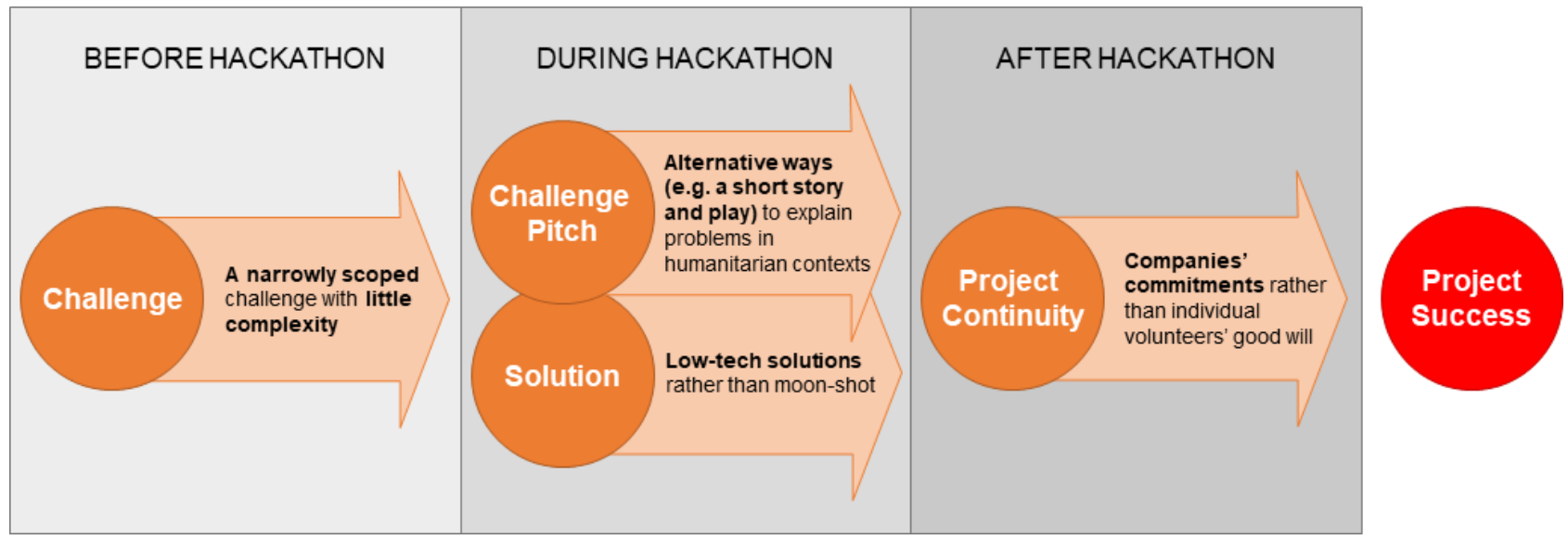

Figure 1 Recommendations based on the lessons learnt.

core challenge was pitched within a short story and play. ${ }^{5}$ Such methods help participants without direct experience of humanitarian work to better understand the contexts in which their proposed solutions must function.

\section{Feasibility versus desirability}

Technological infeasibility is a common pitfall for projects conceived during a hackathon. ${ }^{6}$ Team 4 originally developed a so-called moon-shot concept. However, even after various attempts to adapt and simplify the proposal, the team members were unable to continue such a project on a voluntary basis. Even team 1, whose concept was much simpler, still faced technological challenges during the iteration phases that ultimately discouraged them from refining their prototype further.

The experiences of teams 1 and 4 indicate that technological feasibility should be assessed early and ideas refined accordingly with particular attention paid to the impact of such refinement on the effectiveness of the proposal. More generally, organisations with extremely limited capacity for product development projects-like MSF-should only consider proposals requiring minimal levels of this sort of investment.

\section{Measures to consider for encouraging project continuation}

MSF and Japan Biodesign offered significant posthackathon support to winning teams. While the importance of this is often stressed to encourage project continuation, ${ }^{7}$ the dissolution of all our winning teams before the end of their respective design processes suggests that follow-up support alone is insufficient. Two specific observations bear highlighting.

First, while the moon-shot proposal initially provoked a noticeably higher level of motivation among the team to continue work, that excitement appears to have been much more vulnerable to the realities of humanitarian work. As those realities forced reiterations that scaled back the ambition of the project, the interest of the team to continue working concurrently diminished, and the quality of their reiterations dropped. This again highlights the benefits of steering teams early towards technologically less-demanding solutions, which are more realistic in typical medical humanitarian contexts.

Second, it is worth inquiring into the interests of volunteers' respective employers in the project their staff produced during the hackathon. This gives opportunity to negotiate a time commitment for which they may release their staff and even explore additional ways those employers might offer help. Employers, especially large companies, may be motivated by a corporate social responsibility policy, development of their human capital or opportunities to raise their own public profile. $^{8}$ On the other hand, small-sized and medium-sized medical device companies may be motivated by finding a new business portfolio by a hackathon. Without such commitments, our experience again highlights the difficulties volunteers face to give sufficient time.

\section{CONCLUSION}

Our Hackathon for Humanitarian Surgical Care produced four interesting projects. We attribute that success to appropriately scoping most of our challenges, emphasising a narrower scope even at the cost of some creative latitude for problem solving. Committing significant posthackathon support to winners allowed the development of some of their ideas to continue for a good amount of time after the event. Nonetheless, all our teams ultimately stopped before reaching the end of their respective design processes. This suggests follow-up support alone is insufficient to achieve tangible solutions from hackathons. We suggest hackathon organisers should additionally steer participants away from technologically demanding solutions, as such moon-shots appear particularly complex to manage and progress with high risk of failure. Organisers should also try and secure a reliable time commitment for the subsequent volunteer work necessary to bring proposals to fruition. This may involve exploring 
the interests of winners' respective employers in the continuation of winning projects.

Acknowledgements We thank the hackathon participants for their dedication to the projects. We also thank Sally Moss (of Sally Moss Editorial) and Martin Searle for their excellent editorial support.

Contributors MK, FI, MY and SDC all contributed their ideas and reflections to write this article. All authors provided approval of the final submission.

Funding The authors have not declared a specific grant for this research from any funding agency in the public, commercial or not-for-profit sectors.

Competing interests None declared.

Patient consent for publication Not required.

Provenance and peer review Not commissioned; externally peer reviewed.

Open access This is an open access article distributed in accordance with the Creative Commons Attribution Non Commercial (CC BYNC 4.0) license, which permits others to distribute, remix, adapt, build upon this work non-commercially, and license their derivative works on different terms, provided the original work is properly cited, appropriate credit is given, any changes made indicated, and the use is non-commercial. See: http://creativecommons.org/ licenses/by-nc/4.0/.

ORCID iD

Michiko Kyokan http://orcid.org/0000-0001-5539-1828

\section{REFERENCES}

1 Angelidis P, Berman L, Casas-Perez MdelaL, et al. The hackathon model to Spur innovation around global mHealth. $J$ Med Eng Technol 2016;40:392-9.

2 IDEO.org. The field guide to Human-Centered design. Palo Alto, CA: IDEO, 2015.

3 Japan Biodesign. Available: http://www.jamti.or.jp/en/biodesign/ program/ [Accessed 29 Jun 2020].

4 MIT Hacking Medicine. Health hackathon handbook. Available: http://hackingmedicine.mit.edu/assets/Health_Hackathon_ Handbook.pdf [Accessed 29 Jun 2020].

5 The Higashiaichi Shimbun. Toyohashi live demonstration course. Available: http://www.higashiaichi.co.jp/news/detail/ 4849 [Accessed 29 Jun 2020].

6 Richards T. Hackathons in the Tech industry: from their role in corporate innovation to recruitment. Techloop. Available: https:/techloop.io/for-companies/hackathons-in-the-techindustry/ [Accessed 29 Jun 2020].

7 Olson KR, Walsh M, Garg P, et al. Health hackathons: theatre or substance? A survey assessment of outcomes from healthcarefocused hackathons in three countries. BMJ Innov 2017;3:3744.

8 Cho SH. Comparative research on corporate social responsibility (Csr): Japan and South Korea, 2019. Available: http://www.f.waseda.jp/glaw/CLASSES/Thesis [Accessed 29 Jun 2020]. 